\title{
Identificação de tipos polínicos não registrados nos estudos aeropalinológicos do Brasil
}

\author{
Identification of pollen types not registered in aeropalinologic studies in Brazil \\ Sandra Maria Vergamini ${ }^{1}$ Adelaide Juvena Kegler Ramos ${ }^{2}$ Leandro Duso $^{3}$ \\ Francieli Sbersi $^{3}$ Taísa Fedrizzi Maffazzioli $^{3}$
}

\section{- NOTA -}

\section{RESUMO}

\begin{abstract}
Os objetivos deste trabalho foram realizar um monitoramento aerobiológico, identificando e quantificando os tipos de grãos de pólen da atmosfera da cidade de Caxias do Sul, RS. Este estudo teve início em janeiro de 2001 e término em dezembro de 2002. As coletas foram realizadas através do captador volumétrico de sucção (HIRST, 1952) modelo Burkard ${ }^{\circledR}$, instalado no telhado do Hospital Geral da Universidade de Caxias do Sul, a uma altura aproximada de 20 metros, não apresentando obstáculos que possam bloquear as massas de ar em nenhuma direção. Durante o período de estudo, foram identificados 40 tipos polínicos. Foram selecionados os tipos polínicos Carya, Melastomataceae, Mimosa scabrella, Myrsine e Sorocea bonplandii por não apresentarem referência nos estudos aeropalinológicos brasileiros consultados, sendo citados pela primeira vez no Calendário Polínico de Caxias do Sul (VERGAMINI, 2003). Temperatura, vento e precipitação foram responsáveis diretos pelas grandes mudanças quantitativas do pólen na atmosfera. Os tipos polínicos Carya $e$ Melastomataceae ocorreram predominantemente na primavera. Mimosa scabrella apresentou maiores concentrações nos meses de inverno e foi considerado o segundo tipo polínico mais incidente. O tipo polínico Myrsine ocorreu principalmente nos meses de outono. O pólen de Sorocea bonplandii ocorreu em todos os meses, sendo mais incidente na primavera e no verão.
\end{abstract}

Palavras-chave: aeropalinologia, pólen, Caxias do Sul.

\section{ABSTRACT}

This research was aimed at realizing the aerobiological monitoring, identifying and quantifying the types of pollen grains in the atmosphere of the city of Caxias do Sul. This study had started in January $1^{\text {st }}, 2001$ and finished in December $31^{\text {st }}$, 2002. The samplings were taken using the volumetric suction sampler (HIRST, 1952), Burkard ${ }^{\circledR}$ model, placed on the roof of the General Hospital in the University of Caxias do Sul, about $20 \mathrm{~m}$ above ground, without nearby obstacles that could interrupt the air flow. During the period of study, 40 pollen types were identified. The pollen types Carya, Melastomataceae, Mimosa scabrella, Myrsine and Sorocea bonplandii were sellected because they were not found in other aeropalinological references, being registered for the first time in Caxias do Sul Pollen Calendar (VERGAMINI, 2003). Temperature, wind and rainfall were the main responsibles for the large pollen quantitative changes in the atmosphere. The pollen types Carya and Melastomataceae occured mainly in Spring. Mimosa scabrella presented higher concentrations in Winter months, and was considered the second more frequent pollen type. Myrsine pollen type occured mainly in the Autumn. Sorocea bonplandii pollen occured in all months, being more frequent in Spring and Summer.

Key words: aeropalinology, pollen, Caxias do Sul.

As concentrações polínicas na atmosfera estão sujeitas não apenas à capacidade de dispersão dos grãos de pólen e aos fatores fenológicos e fitogeográficos, mas também aos elementos meteorológicos, como temperatura (máxima, média e mínima), precipitação, umidade relativa, velocidade do vento, insolação e evaporação, sendo este último

\footnotetext{
${ }^{1}$ Departamento de Educação, Universidade de Caxias do Sul (UCS). Rua Francisco Getúlio Vargas, 1130, 95070-560, Caxias do Sul, RS, Brasil. E-mail: smvergam@ucs.br. Autor para correspondência.

${ }^{2}$ Associação Riograndense de Empreendimentos de Assistência Técnica e Extensão Rural (EMATER), Caxias do Sul, RS, Brasil. ${ }^{3} \mathrm{UCS}$, Caxias do Sul, RS, Brasil.
} 
considerado pela primeira vez em estudos aeropalinológicos realizados no Brasil.

As investigações aeropalinológicas estão bastante avançadas nos grandes centros urbanos do Hemisfério Norte. Na América Latina, este campo tem sido pouco explorado. No que concerne ao Brasil, só há um calendário polínico completo, realizado em Caxias do Sul (VERGAMINI, 2003).

Cinco tipos polínicos não apresentam registros em estudos aeropalinológicos consultados do Brasil: Carya, Melastomataceae, Mimosa scabrella, Myrsine e Sorocea bonplandii (VERGAMINI, 2003).

Para a obtenção das amostras de pólen aéreas, foi utilizado o captador volumétrico de sucção (HIRST, 1952) modelo Burkard®, instalado no alto do Hospital Geral da Universidade de Caxias do Sul, a uma altura aproximada de 20 metros, nas coordenadas 22J0484862UTM6774144, não havendo obstáculos que bloqueiem a chegada de massas de ar de nenhuma direção.

O captador manteve uma entrada de ar constante de $10 \mathrm{~L} \mathrm{~min}^{-1}$, que incidiu sobre uma superfície de captura (fita de melinex) impregnada com silicone, na qual se fixaram as partículas aéreas, o que incluiu os grãos de pólen. Essa fita, trocada semanalmente, foi cortada em sete partes, que corresponderam aos sete dias da semana. Após isso, foram confeccionadas lâminas utilizando-se glicerogelatina com fucsina, que foram observadas por microscopia ótica para identificação e quantificação dos grãos de pólen.

As preparações foram analisadas com um microscópio ótico Leica DMLS e a sua leitura realizouse de acordo com o postulado de DOMÍNGUEZ VILCHES et al. (1991), segundo o qual se realizam 4 varreduras longitudinais eqüidistantes, utilizando uma objetiva de aumento 40x. As concentrações polínicas foram expressas em grãos $\mathrm{m}^{-3} \mathrm{de}$ ar.

As identificações polínicas basearam-se numa coleção de referência, a palinoteca, confeccionada com material fresco ou herborizado da região, como também numa bibliografia especializada, como HYDE \& ADAMS (1958), GRANT SMITH (1986), VALDÉS et al. (1987), MOORE et al. (1991), PIRE et al. (1998).

Durante os dois anos de estudo, registrouse pólen na atmosfera de Caxias do Sul ao longo de todos os meses. Entre os 40 tipos polínicos identificados, foram coletados, nos dois anos de estudo, 3.0469 grãos $\mathrm{m}^{-3}$, sendo que os cinco tipos polínicos aos quais se faz referência neste trabalho Carya, Melastomataceae, Mimosa scabrella, Myrsine e Sorocea bonplandii - corresponderam a $28,57 \%$ do total, com 8.704 grãos $\mathrm{m}^{-3}$ coletados (Figura 1).
O tipo polínico Mimosa scabrella, em 2001, apresentou um total de 3.656 grãos $\mathrm{m}^{-3}$ e uma porcentagem correspondente a $22,54 \%$ do total anual. Em 2002, atingiu uma porcentagem de $14,65 \%$ e um total de 2087 grãos $\mathrm{m}^{-3}$. Entre os 18 tipos polínicos do calendário, foi o segundo mais incidente do período de estudo, apresentando as maiores concentrações em agosto. Mimosa scabrella provém de uma planta pouco exigente quanto às condições físicas do solo, necessitando, no entanto, de plena exposição à radiação solar, sendo encontrada, devido a isto, em matas abertas.

O tipo polínico Myrsine está representado no município pelas seguintes espécies: Myrsine ferruginea, M. laetevirens, M. lineata, $M$. megapotamica e $\boldsymbol{M}$. umbellata, espécies heliófitas, características de estágios sucessionais secundários. Em 2001, apresentou um total de 937 grãos $\mathrm{m}^{-3}$ e uma porcentagem correspondente a 5,77\% do total anual. Em 2002, atingiu uma porcentagem de 3,79\% e um total de 539 grãos $\mathrm{m}^{-3}$. Ocorreu predominantemente em abril.

O tipo polínico Sorocea bonplandii (Moraceae), espécie característica de sub-bosque de matas primárias, apresentou índices mais elevados em novembro e dezembro. Em 2001, registrou-se um total de 577 grãos $\mathrm{m}^{-3}$ e uma porcentagem correspondente a $3,56 \%$ do total anual. Em 2002, atingiu uma porcentagem de $4,30 \%$ e um total de 613 grãos $\mathrm{m}^{-3}$.

A família Melastomataceae está representada no município pelas espécies Leandra balduinii, L. catharinensis, L. laevigata, L. macropora, L. regnelli, L. riograndensis, $L$. sublanata, L. xanthocoma, Miconia cinerascens, $M$. hyemalis, M. inconspicua, M. sellowiana, Tibouchina cf. cerastifolia, T. cisplatensis, T. gracilis, $T$. longipilosa, T. moricandiana e T. rupestris. São espécies pioneiras, exigentes em luminosidade. $\mathrm{O}$ gênero Miconia ocorre nos estágios secundários iniciais, sendo que, nos demais estágios, aparece somente em clareiras. Os gêneros Tibouchina e Leandra são comuns em áreas exploradas, preferencialmente em ambientes úmidos; nos estágios de sucessão secundária e primária, ocorrem somente em áreas abertas. Este tipo polínico apresentou maior incidência em setembro e novembro, com um total de 70 grãos $\mathrm{m}^{-3}$ e uma porcentagem correspondente a $0,43 \%$ do total anual em 2001. Em 2002, atingiu uma porcentagem de $0,69 \%$ e um total de 98 grãos $\mathrm{m}^{-3}$. A única referência encontrada sobre sua incidência na atmosfera foi citada na cidade de Posadas (Argentina) por PAUL et al. (2000).

Em Caxias do Sul, a família Juglandaceae está representada por uma única espécie, Carya illinoensis, 


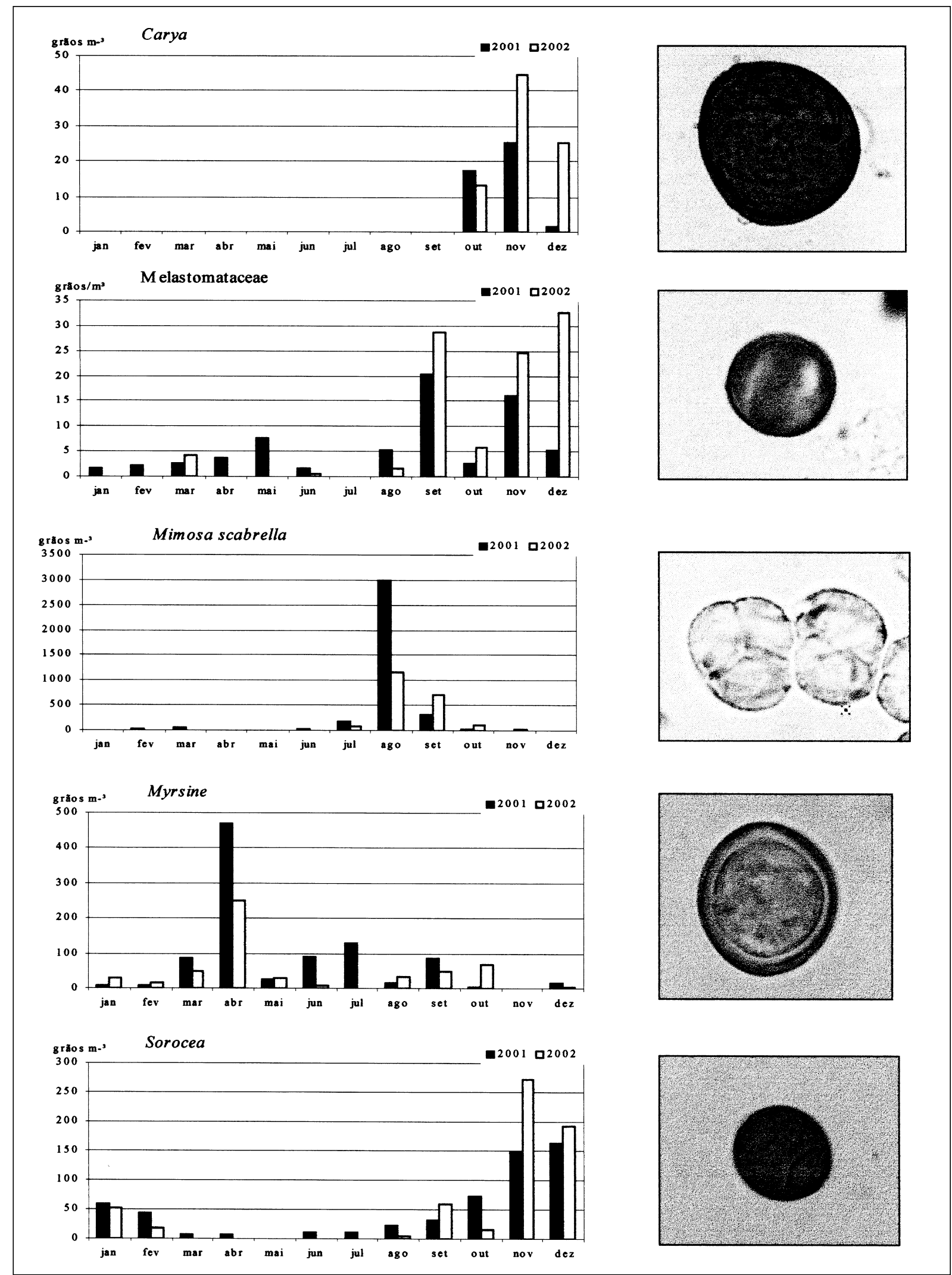

Figura 1 - Concentrações mensais dos cinco tipos polínicos no período de estudo e respectiva fotografia do pólen em microscopia ótica, utilizando objetiva de 40 aumentos.

Ciência Rural, v.36, n.6, nov-dez, 2006. 
espécie originária da América do Norte. O tipo polínico Carya é essencialmente primaveril, ocorrendo, predominantemente, em novembro. Apresentou uma permanência na atmosfera de 52 dias no ano de 2001, com total de 44 grãos $\mathrm{m}^{-3}$ e uma porcentagem correspondente a $0,27 \%$ do total anual. Em 2002, apresentou permanência de 70 dias na atmosfera e atingiu uma porcentagem de $0,58 \%$, com total de 83 grãos $\mathrm{m}^{-3}$. A variação no total anual foi de $50 \%$ entre os dois anos de estudo. Resultados semelhantes quanto à incidência polínica e à concentração mensal foram encontrados na Argentina por MAJAS \& ROMERO (1992), NOETINGER (1993), LATORRE \& PÉREZ(1997) e PÉREZ \& PAEZ (1998).

Dos cinco tipos polínicos citados, Mimosa scabrella apresentou maior incidência de grãos de pólen, enquanto o tipo polínico Carya registrou as menores concentrações do período.

A polinização dos cinco tipos polínicos ocorreu predominantemente na primavera e no verão. Porém, a maior concentração de grãos de pólen deu-se no inverno, devido ao tipo polínico Mimosa scabrella.

\section{REFERÊNCIAS}

DOMÍNGUEZ VILCHES, E. et al. Manejo y evaluación de los datos obtenidos en los muestros aerobiológicos, v.1, p.1-18, 1991.

GRANT SMITH, E. Sampling and identifying allergenic pollens and molds. San Antonio, Texas: Blewstone, 1986. V.2. $98 p$.
HIRST, J.M. An automatic volumetric spore-trap. Annals Applied Biology, v.36, p.257-265, 1952.

HYDE H.A.; ADAMS, K.F. An atlas of airborne pollen grains. New York: St. Martin's, 1958. 112p.

LATORRE, F.; PÉREZ, C.F. One year of airborne pollen sampling in Mar del Plata (Argentina). Grana, v.36, p.49-53, 1997.

MAJAS, F.D.; ROMERO, E.J. Aeropalynological research in the Northeast of Buenos Aires Province, Argentina. Grana, v.31, p.143-156, 1992.

MOORE, P.D. et al. Pollen analysis. Oxford: Blackwell Scientific Publications, 1991. 216p.

NOETINGER, M. Tres años de monitoreo de la lluvia polinica en la Ciudad de Buenos Aires. Archivos Argentinos de Alergia e Inmunología Clínica, v.24, n.2, p.65-75, 1993.

PAUL, R.M. et al. Análisis de la lluvia polínica de la Ciudad de Posadas, Misiones, Argentina. Revista de Ciencia y Tecnologia, v.3, 2000.

PÉREZ, C.F.; PAEZ, M.M. Seasonal airbone pollen in Mar del Plata City, Argentina. Aerobiologia, v.14, p.383-389, 1998.

PIRE, S.M. et al. Flora polínica del Nordeste Argentino. Corrientes, Argentina: Eudene, 1998. v.1, 143p.

VALDÉS, B. et al. Atlas polinico de Andalucía Occidental. Sevilla: Inst. de desarrollo Regional de la Universidad de Sevilla. Sevilla. Excma. Diputación de Cádiz, 1987. 451p.

VERGAMINI, S.M. Estudo polínico da atmosfera de Caxias do Sul (Rio Grande do Sul, Brasil). 2003. 334f. Tese (Doutorado em Biologia Ambiental) - Universidade de Caxias do Sul. 